\title{
Technical note: Simultaneous carotenoid and vitamin analysis of milk from total mixed ration-fed cows optimized for xanthophyll detection
}

\author{
M. A. Stout, D. M. Benoist, and M. A. Drake ${ }^{1}$ \\ Department of Food, Bioprocessing and Nutrition Science, Southeast Dairy Foods Research Center, North Carolina State University, \\ Raleigh 27695
}

\begin{abstract}
Concentrations of retinol, $\alpha$-tocopherol, and major carotenoids in dairy products are often determined simultaneously by liquid chromatography. These compounds have different polarity and solubility; thus, extracting them simultaneously can be difficult and inefficient. In milks with low carotenoid concentrations, the xanthophylls lutein and zeaxanthin may not be completely resolved using common extraction techniques. A simplified method was developed to optimize extraction efficiency and the limit of detection and limit of quantification (LoQ) of lutein and zeaxanthin in bovine milk without decreasing sensitivity to other vitamins or carotenoids. The developed method evaluates lutein, zeaxanthin, $\beta$-carotene, retinol, and $\alpha$-tocopherol simultaneously by ultra-high performance liquid chromatography-photodiode array detection. Common saponification temperatures $\left(40-60^{\circ} \mathrm{C}\right)$ and concentrations of $\mathrm{KOH}$ in water $(10-50 \% \mathrm{KOH}$ wt/ vol) were evaluated. Multiple solvents were evaluated for optimal xanthophyll extraction (diethyl ether, dichloromethane, hexane, and tetrahydrofuran) following saponification. The limit of detection and LoQ were defined as 3:1 and 10:1 signal-to-noise ratio, respectively. All experiments were performed in triplicate. The optimal saponification procedure was a concentration of $25 \% \mathrm{KOH}$ at either 40 or $50^{\circ} \mathrm{C}$. Saponified extracts solubilized in solutions containing diethyl ether had greater concentrations of lutein- than hexane- or tetrahydrofuran-based solutions, with peak areas above LoQ values. The solution containing diethyl ether solubilized similar concentrations of retinol, $\alpha$-tocopherol, and $\beta$-carotene when compared with other solutions. The proposed optimized method allows for the simultaneous determination of carotenoids from milk with increased lutein and zeaxanthin sensitivity without sacrificing recovery of retinol, $\alpha$-tocopherol, and $\beta$-carotene.
\end{abstract}

Key words: carotenoids, milk, extraction

Received April 29, 2017.

Accepted January 8, 2018.

${ }^{1}$ Corresponding author: maryanne_drake@ncsu.edu

\section{Technical Note}

The carotenoids, $\beta$-carotene and xanthophylls, such as lutein and zeaxanthin, are among the most common carotenoids found in milk (Nozière et al., 2006; Plozza et al., 2012; Gill et al., 2016). Changes in carotenoid concentration in bovine feed affect carotenoid content in bovine milk (Calderón et al., 2007a). Thus, accurate detection of $\beta$-carotene, lutein, and zeaxanthin in bovine milk can serve as a marker for diet quality of dairy cows (Prache et al., 2002; Martin et al., 2005; Butler et al., 2008) and traceability of feed management in dairy cows (Calderón et al., 2007a) and can also play a role in human health (Kohlmeier and Hastings, 1995; Rapp et al., 2000; Macias and Schweigert, 2001; Jewell et al., 2004; Schweigert et al., 2004).

Retinol, $\alpha$-tocopherol, and carotenoids in bovine milk are often determined simultaneously by solvent extraction followed by ultra-high performance liquid chromatography-photodiode array detection (UPLCPDA) or MS (Indyk, 1987; Ollilainen et al., 1989; Giuliano et al., 1992; Jinno and Lin, 1995; Oliver and Palou, 2000; Turne et al., 2001; Blake, 2007; Calderón et al., 2007b; Kamao et al., 2007; Chauveau-Duriot et al., 2010; Plozza et al., 2012; Gentili et al., 2013). However, unlike $\beta$-carotene, the xanthophylls lutein and zeaxanthin are difficult to quantify in milks with low carotenoid content using UPLC-PDA detection (Nozière et al., 2006). Chauveau-Duriot et al. (2010) reported that lutein in whole milks was below the limit of quantification (LoQ) and occasionally below the limit of detection (LoD) using a UPLC-PDA method, although they were detected using other instrumental techniques such as MS (Gentili et al., 2013). Percent recovery for lutein was below $70 \%$ in Chauveau-Duriot et al. (2010). Gill and Indyk (2008) designed a method to determine lutein in milk with a percent recovery of lutein $>95 \%$; however, this method was not optimized for fat-soluble vitamins or carotenes. Lutein concentration in bovine milk is dependent on feed and total fat content (Havemose et al., 2004). Milk of cows fed a TMR contains approximately 20 to $60 \%$ less lutein than pasture-fed cows (Nozière et al., 2006; Havemose 
et al., 2004). Lower concentrations of total lutein in TMR milks may prevent accurate lutein determination.

Several factors that may limit lutein recovery rates are saponification parameters and lutein solvent affinity. Saponification is often necessary to remove carotenoids from lipids in samples containing fat (Giuliano et al., 1992; Calderón et al., 2007b; Gill et al., 2016); however, heat and caustic solutions used in saponification can result in lutein degradation (Khachik et al., 1997; Salo-Väänänena et al., 2000; Gill and Indyk, 2008). Granelli and Helmersson (1996) demonstrated $30^{\circ} \mathrm{C}$ to be sufficient for complete recovery of $\beta$-carotene, despite the claim by Indyk (1987) that high-temperature saponification was needed for complete extraction of carotenoids and retinol from milk fat. Thus, determining the temperature and $\mathrm{KOH}$ concentration during saponification may contribute to increased lutein and zeaxanthin recovery rates while preserving $\beta$-carotene and retinol recovery rates.

Although xanthophylls and carotenes are chemically similar, the electron density on the oxygen atoms of xanthophylls can influence polarity and solubility (Mortensen and Skibsted, 1997; Yan et al., 2007). Simultaneous extraction of carotenoids and fat-soluble vitamins in bovine milk may be influenced by these solubility differences (Craft and Soares, 1992; Indyk, 1987; Gill et al., 2016). Previous methods have used extraction solutions containing hexane, dichloromethane, tetrahydrofuran (THF), acetonitrile, and ethanol (Granelli and Helmersson, 1996; Giuliano et al., 1992; Chauveau-Duriot et al., 2010; Plozza et al., 2012); however, Craft and Soares (1992) demonstrated that lutein solubilized poorly in hexane and has reduced solubility in dichloromethane compared with $\beta$-carotene. Although rarely used in carotenoid extraction of milk, previous research has shown that diethyl ether could efficiently solubilize both lutein and $\beta$-carotene (Craft and Soares, 1992; Oliver and Palou, 2000). No study to our knowledge has determined if a particular solvent optimizes lutein and zeaxanthin extraction without affecting $\beta$-carotene, retinol, and $\alpha$-tocopherol extraction.

Previous research for simultaneous carotenoid and fat-soluble vitamin determination in fluid milk may not consistently detect xanthophylls above the LoQ. This may be due to aggressive saponification parameters and inadequate solubility. The objective of our study was to determine an extraction and purification method that optimized lutein detection without reducing the detection of other carotenoids and vitamins.

Saponification conditions and extraction solvents following saponification were compared to determine the optimal conditions for extraction and measurement of carotenoids (including lutein) and fat-soluble vitamins by UPLC-PDA. The verification of the method through measurement of commercial bovine milks, from both pasture- and TMR-fed cows, was then conducted.

Reagent-grade solvents (ethanol, ethyl acetate, and hexane), HPLC-grade THF and acetonitrile, and $>99 \%$ crystalline retinol, $\geq 99.5 \% \beta$-carotene, $\geq 99.5 \%$ zeaxanthin, $\geq 99.5 \%$ lutein, and $\geq 99.0 \% \alpha$-tocopherol were purchased from Sigma-Aldrich (St. Louis, MO). The HPLC-grade water, diethyl ether, hexane, ethanol, and methanol were purchased from Fluka (Seelze, Germany). Reagent-grade $\mathrm{KOH}$ was purchased from VWR (Randor, PA).

All milks were extracted and prepared with overhead lights off to prevent light oxidation. Three milliliters of each milk was incorporated into a container with ethyl alcohol and a saponification solution containing various concentrations of $\mathrm{KOH}$ and deionized water (Table 1; described below). Samples were flushed with nitrogen, capped with a polytetrafluoroethylene-lined cap, and sonicated for 5 min. Samples were placed in a water bath at varying temperatures for $30 \mathrm{~min}$ as a saponification step (Table 1). After saponification, $6 \mathrm{~mL}$ of hexane:ethyl acetate (70:30) was poured into each vial, vortexed, sonicated for $5 \mathrm{~min}$, and centrifuged at $800 \times$ $g$ for $10 \mathrm{~min}$ at $25^{\circ} \mathrm{C}$. The organic layer was then separated from the aqueous layer and the aqueous phase was treated with an additional $3 \mathrm{~mL}$ of hexane:ethyl acetate (70:30). This complex was then vortexed, sonicated for $5 \mathrm{~min}$, and centrifuged again at $800 \times g$ for 10 min at $25^{\circ} \mathrm{C}$. The resulting organic phase was removed and added to the original organic phase removed. This process was repeated a third time. The pooled extract was evaporated to dryness under nitrogen. The dried sample was then dissolved in $700 \mu \mathrm{L}$ of a solution containing HPLC-grade ethanol, acetonitrile, and water at a concentration of $58: 18: 4$; the final $20 \%$ of that solution was varied (Table 2, described below). Samples were then filtered with a $0.20-\mu \mathrm{m}$ nylon filter (VWR) and placed in HPLC vials (Sigma-Aldrich). Finally, 3.0 $\mu \mathrm{L}$ was injected onto the UPLC.

Lutein, $\beta$-carotene, retinol, zeaxanthin, and $\alpha$-tocopherol were analyzed by UPLC (Acquity UPLC H-Class, Waters Corporation, Milford, MA) with a C18 reversed phase column (Acquity UPLC BEH C18 1.7 $\mu \mathrm{m}, 2.1 \times 50 \mathrm{~mm}, 130 \AA$, Waters). The column temperature was maintained at $32^{\circ} \mathrm{C} \pm 0.3^{\circ} \mathrm{C}$, whereas flow rate was maintained at $0.30 \mathrm{~mL} / \mathrm{min}$ (Acquity UPLC HClass, Quaternary Solvent Manager, Waters). Aliquots of each sample were then eluted with the respective mobile phase (described below). Peaks were analyzed by photodiode array detection (Acquity UPLC H-Class, Photodiode Array Detector, Waters) with wavelengths monitored at $448 \mathrm{~nm}$ for $\beta$-carotene and zeaxanthin, 
Table 1. Mean effect of saponification parameters (percent $\mathrm{KOH}$ and temperature) for 30 min on carotenoid and fat-soluble vitamin concentrations in TMR milks $(\mathrm{n}=36)$

\begin{tabular}{|c|c|c|c|c|c|}
\hline $\begin{array}{l}\text { Saponification } \\
\text { parameter }^{1}\end{array}$ & $\begin{array}{c}\text { Lutein } \\
(\mu \mathrm{g} / 100 \mathrm{~mL})\end{array}$ & $\begin{array}{l}\text { Zeaxanthin } \\
(\mu \mathrm{g} / 100 \mathrm{~mL})\end{array}$ & $\begin{array}{l}\beta \text {-Carotene } \\
(\mu \mathrm{g} / 100 \mathrm{~mL})\end{array}$ & $\begin{array}{c}\text { Retinol } \\
(\mu \mathrm{g} / 100 \mathrm{~mL})\end{array}$ & $\begin{array}{r}\alpha \text {-Tocopherol } \\
(\mu \mathrm{g} / 100 \mathrm{~mL})\end{array}$ \\
\hline $10 \% 25^{\circ} \mathrm{C}$ & $1.64^{\mathrm{BC}}$ & $\mathrm{NQ}^{2}$ & $7.35^{\mathrm{C}}$ & $18.75^{\mathrm{CD}}$ & $38.41^{\mathrm{BC}}$ \\
\hline $10 \% 40^{\circ} \mathrm{C}$ & $1.48^{\mathrm{C}}$ & $0.78^{\mathrm{AB}}$ & $6.81^{\mathrm{C}}$ & $18.21^{\mathrm{CD}}$ & $38.37^{\mathrm{BC}}$ \\
\hline $10 \% 50^{\circ} \mathrm{C}$ & $1.89^{\mathrm{A}}$ & NQ & $6.57^{\mathrm{C}}$ & $18.16^{\mathrm{CD}}$ & $39.84^{\mathrm{BC}}$ \\
\hline $10 \% 60^{\circ} \mathrm{C}$ & $1.57^{\mathrm{C}}$ & NQ & $7.06^{\mathrm{C}}$ & $20.32^{\mathrm{ABCD}}$ & $40.89^{\mathrm{AB}}$ \\
\hline $25 \% 25^{\circ} \mathrm{C}$ & $1.22^{\mathrm{D}}$ & NQ & $8.07^{\mathrm{BC}}$ & $17.43^{\mathrm{D}}$ & $40.18^{\mathrm{ABC}}$ \\
\hline $25 \% 40^{\circ} \mathrm{C}^{3}$ & $2.02^{\mathrm{A}}$ & $0.82^{\mathrm{A}}$ & $9.74^{\mathrm{A}}$ & $23.24^{\mathrm{A}}$ & $43.83^{\mathrm{A}}$ \\
\hline $25 \% 50^{\circ} \mathrm{C}$ & $1.85^{\mathrm{AB}}$ & $0.75^{\mathrm{B}}$ & $10.34^{\mathrm{A}}$ & $22.03^{\mathrm{AB}}$ & $42.30^{\mathrm{AB}}$ \\
\hline $25 \% 60^{\circ} \mathrm{C}$ & $1.58^{\mathrm{C}}$ & NQ & $9.18^{\mathrm{AB}}$ & $20.55^{\mathrm{ABC}}$ & $39.64^{\mathrm{BC}}$ \\
\hline $50 \% 25^{\circ} \mathrm{C}$ & $1.61^{\mathrm{C}}$ & $0.74^{\mathrm{B}}$ & $7.29^{\mathrm{C}}$ & $18.41^{\mathrm{CD}}$ & $36.64^{\mathrm{C}}$ \\
\hline $50 \% 40^{\circ} \mathrm{C}$ & $1.87^{\mathrm{A}}$ & $\mathrm{ND}^{4}$ & $10.11^{\mathrm{A}}$ & $22.44^{\mathrm{AB}}$ & $40.18^{\mathrm{ABC}}$ \\
\hline $50 \% 50^{\circ} \mathrm{C}$ & $1.15^{\mathrm{D}}$ & ND & $10.70^{\mathrm{A}}$ & $21.01^{\mathrm{ABC}}$ & $40.57^{\mathrm{ABC}}$ \\
\hline $50 \% 60^{\circ} \mathrm{C}$ & $1.12^{\mathrm{D}}$ & ND & $9.92^{\mathrm{A}}$ & $19.85^{\mathrm{BCD}}$ & $41.47^{\mathrm{AB}}$ \\
\hline$P>\mathrm{F}$ & $<0.0001$ & $<0.0001$ & $<0.0001$ & 0.005 & 0.05 \\
\hline $\mathrm{R}^{2}$ & 0.880 & 0.979 & 0.802 & 0.613 & 0.471 \\
\hline
\end{tabular}

${ }^{\mathrm{A}-\mathrm{D}}$ Means in a column not sharing a common letter are different $(P<0.05)$.

${ }^{1}$ Represented as percent $\mathrm{KOH}$ used in each treatment followed by the temperature at which the treatment was done for $30 \mathrm{~min}$.

${ }^{2} \mathrm{NQ}=$ not quantified. Samples were detected, but were measured below LoQ.

${ }^{3}$ Saponification of $25 \% \mathrm{KOH}$ at $40^{\circ} \mathrm{C}$ for $30 \mathrm{~min}$ is the process used in the proposed method.

${ }^{4} \mathrm{ND}=$ not detected.

$325 \mathrm{~nm}$ for retinol, $294 \mathrm{~nm}$ for $\alpha$-tocopherol, and 444 nm for lutein (Craft and Soares, 1992; Giuliano et al., 1992; MacCrehan and Schönberger, 1987).

Six calibration standards were prepared for each compound tested. Standards were diluted with a 58:18:20:4 solution containing HPLC-grade ethanol, acetonitrile, diethyl ether, and water. The concentration of each standard solution was verified spectrophotometrically, as outlined by Craft and Soares (1992). Standards were diluted to various concentrations to develop a 6-point standard curve. Compound concentrations were derived from these standard curves.

Four temperatures and 3 concentrations of $\mathrm{KOH}$ were compared, which encompassed most variability among published carotenoid saponification methods (Ollilainen et al., 1989; Granelli and Helmersson, 1996). The temperatures selected were $25,40,50$, and $60^{\circ} \mathrm{C}$. To test the effect of $\mathrm{KOH}$ concentration on lutein recovery, $\mathrm{KOH}$ solutions were prepared with 10, 25, and $50 \%$ $\mathrm{KOH}$ in deionized water (wt/vol) and added during the saponification procedure with 1 of the 3 temperatures.

Following evaporation to dryness, carotenoids and fat-soluble vitamins were solubilized into a solvent (Gill and Indyk, 2008; Oliver and Palou, 2000; Delgado Zammarreño et al., 1992) so that analytes could then be injected as a liquid onto a UPLC/HPLC column. This is typically performed using a solution containing several solvents, as this step must adequately solubilize all compounds for proper injection (Delgado Zammarreño et al., 1992; Oliver and Palou, 2000; Gill and Indyk, 2008). To identify a final diluent that was optimized for lutein and zeaxanthin, common nonpolar solvents were compared at a concentration of $20 \%$ in a standardized diluent solution containing ethanol, acetonitrile,

Table 2. The role of variable standard extraction solution (ethanol: acetonitrile: water 58:18:4) with $20 \%$ of the solvent or solution specified $(\mathrm{n}=12)$ postsaponification on mean carotenoid and vitamin concentration from TMR milk

\begin{tabular}{lccccc}
\hline Solution & $\begin{array}{c}\text { Lutein } \\
(\mu \mathrm{g} / 100 \mathrm{~mL})\end{array}$ & $\begin{array}{c}\text { Zeaxanthin } \\
(\mu \mathrm{g} / 100 \mathrm{~mL})\end{array}$ & $\begin{array}{c}\beta \text {-Carotene } \\
(\mu \mathrm{g} / 100 \mathrm{~mL})\end{array}$ & $\begin{array}{c}\text { Retinol } \\
(\mu \mathrm{g} / 100 \mathrm{~mL})\end{array}$ & $\begin{array}{c}\alpha \text {-Tocopherol } \\
(\mu \mathrm{g} / 100 \mathrm{~mL})\end{array}$ \\
\hline Diethyl ether ${ }^{1}$ & $1.95^{\mathrm{A}}$ & $0.79^{\mathrm{A}}$ & $8.96^{\mathrm{A}}$ & $22.36^{\mathrm{A}}$ & $42.18^{\mathrm{A}}$ \\
Hexane & $1.62^{\mathrm{C}}$ & $\mathrm{NQ}^{2}$ & $8.52^{\mathrm{A}}$ & $21.08^{\mathrm{A}}$ & $39.40^{\mathrm{A}}$ \\
Hexane/THF & $1.71^{\mathrm{BC}}$ & $\mathrm{NQ}^{\mathrm{AB}}$ & $8.84^{\mathrm{A}}$ & $18.98^{\mathrm{A}}$ & $39.70^{\mathrm{A}}$ \\
Dichloromethane & $1.81^{\mathrm{AB}}$ & $0.76^{\mathrm{B}}$ & $9.04^{\mathrm{A}}$ & $22.91^{\mathrm{A}}$ & $41.05^{\mathrm{A}}$ \\
$P>\mathrm{F}$ & 0.017 & $<0.0001$ & 0.337 & 0.315 & 0.798 \\
$\mathrm{R}^{2}$ & 0.502 & 0.998 & 0.324 & 0.342 & 0.113 \\
${ }^{\mathrm{A}-\mathrm{C}}$ Means in a column not sharing a common letter are different $(P<0.05)$. \\
${ }^{1}$ Diethyl ether is the solvent used for the proposed method. \\
${ }^{2} \mathrm{NQ}=$ not quantified. Samples were detected, but were measured below LoQ.
\end{tabular}


and water (58:18:4). Methods vary slightly in specific concentrations of ethanol or acetonitrile, but the focus of this optimization was the ability of the nonpolar solution to solubilize compounds specifically; therefore, a standardized solution was developed containing ethanol, acetonitrile, water, and the solvent being tested at a concentration of 58:18:4:20, respectively (Oliver and Palou, 2000; Giuliano et al., 1992; Gill and Indyk, 2008). Additionally, THF is a strong nonpolar solvent that was observed to cause excessive peak broadening when used in high concentrations (Jinno and Lin, 1995). A solution of THF:hexane (50:50) was prepared similar to conditions seen in literature, and added at the same rate (20\% added to the standard solution) as the other solvents. Samples from 1 lot of TMR milk were prepared and dried using the proposed protocol and solubilized in each of the solvents tested before being evaluated using the proposed UPLC procedure for total concentration of lutein, zeaxanthin, retinol, $\alpha$-tocopherol, and $\beta$-carotene. This experiment required the measurement of compounds in various solutions; however, the standard curve used in the proposed method is specific to the proposed extraction solution. Thus, for our experiment, individual standard curves for each compound were developed in each solution to ensure accuracy between measurements.

The performance of the identified method was then evaluated by the percent recovery, the linear regression of the standard curve, the reproducibility between days, the reproducibility on the same day, and the LoD and LoQ. The percent recovery of all compounds was determined for this method by spiking ethyl ether with each standard and subjecting them to extraction conditions $(n=6)$. Standards of lutein, zeaxanthin, $\beta$-carotene, retinol, and $\alpha$-tocopherol were also spiked in milk solutions at rates of 2.00, 1.5, 9.00, 20.0, and $40.0 \mu \mathrm{g} / 100 \mathrm{~mL}$, respectively, to verify recovery rates in solution. These rates were chosen to best approximate native levels in bovine milk. The linear regression and coefficient of determination of the standard curves for each compound were determined from the calibration standards described in the chromatographic conditions. Reproducibility between days was determined by the residual standard deviation (RSD) between peak areas of compounds from whole commercial bovine milk extracted and analyzed on different days $(\mathrm{n}=6)$. Similarly, the reproducibility on the same day was determined by the RSD between peak areas of compounds extracted and analyzed from whole commercial bovine milk on the same day $(\mathrm{n}=6)$. The $\mathrm{LoD}$ and LoQ were defined as a signal-to-noise ratio of 3:1 and 10:1, respectively, in whole commercial bovine milk $(\mathrm{n}=6$, ChauveauDuriot et al., 2010; Schweigert, et al., 2004; Gill and Indyk, 2008). Finally, the method was validated by evaluating concentrations of lutein, zeaxanthin, retinol, $\beta$-carotene, and $\alpha$-tocopherol in 10 commercial pasteurized whole bovine milks, 5 milks from pasture-fed cows, and 5 milks from TMR-fed cows.

All statistical values were determined by ANOVA with means separation using XLSTAT software (version 2015.3.01; Addinsoft, New York, NY). Differences among sample means were determined through Fisher's least significant difference tests.

Percent recovery of lutein was optimal under several $\mathrm{KOH}$ concentrations and temperatures, including $10 \% \mathrm{KOH}$ at $50^{\circ} \mathrm{C}, 25 \% \mathrm{KOH}$ at $40^{\circ} \mathrm{C}, 25 \% \mathrm{KOH}$ at $50^{\circ} \mathrm{C}$, and $50 \% \mathrm{KOH}$ at $40^{\circ} \mathrm{C}(P<0.05$; Table 1$)$. Zeaxanthin recovery was also optimal under $25 \% \mathrm{KOH}$ at $40^{\circ} \mathrm{C}$, as well as at $10 \% \mathrm{KOH}$ at $40^{\circ} \mathrm{C}(P<0.05)$. Concentrations of $\beta$-carotene and retinol were generally lower in samples subject to $10 \% \mathrm{KOH}$ solutions or lower temperatures $(P<0.05)$. This result supports previous claims that saponification is necessary to fully separate fat-soluble compounds from milk fat (Indyk 1987; Gill and Indyk 2008; Chauveau-Duriot et al., 2010). Ideal saponification parameters were determined to be either a $25 \% \mathrm{KOH}$ at 40,50 , or $60^{\circ} \mathrm{C}$ as well as $50 \% \mathrm{KOH}$ at 40,50 , or $60^{\circ} \mathrm{C}(P<0.05)$. Although Gill and Indyk (2008) demonstrated that increased saponification time can reduce total recovery of lutein, Granelli and Helmersson (1996) reported that saponification of 30 min was adequate for $\beta$-carotene extraction from whole milk. Thus, the variables of temperature and $\mathrm{KOH}$ concentration were evaluated for $30 \mathrm{~min}$ to determine an optimal range. Thirty minutes was long enough to observe lutein and zeaxanthin concentrations drop in high-temperature treatments, likely due to degradation. Retinol and $\alpha$-tocopherol concentrations were both optimal under saponification parameters involving 25 to $50 \% \mathrm{KOH}$ and temperature at 40 to $60^{\circ} \mathrm{C}$. Thus, the ideal saponification parameters were determined to be $25 \% \mathrm{KOH}$ at 40 or $50^{\circ} \mathrm{C}$ for xanthophyll extraction without compromising the extraction of other compounds. A temperature of $40^{\circ} \mathrm{C}$ was selected for the presented method, although a temperature of $50^{\circ} \mathrm{C}$ should provide similar extraction efficiency.

Standardized extraction solutions containing ethanol, acetonitrile, and water were evaluated with $20 \%$ diethyl ether, dichloromethane, hexane alone, or THF: hexane (50:50 vol/vol; Table 2). Milks extracted with the solution containing diethyl ether had more lutein than samples extracted with hexane or THF/hexane $(P<0.05)$, although no difference in lutein content was seen between samples extracted in solutions containing diethyl ether and those extracted with solutions containing dichloromethane $(P>0.05)$. Milks extracted with solutions containing diethyl ether contained more zeaxanthin than those extracted with any other solution 
Table 3. Percent recovery and linear regression of standard curves in whole bovine milk spiked with each standard and extracted using the proposed method

\begin{tabular}{lclc}
\hline Compound & Percent recovery & $\begin{array}{l}\text { Linear regression } \\
\text { of the standard curve }\end{array}$ & $\mathrm{R}^{2}$ \\
\hline Lutein & $98.4 \pm 4.6$ & $\mathrm{y}=2,965.0 \mathrm{x}-4,280.6$ & 0.9963 \\
Zeaxanthin & $91.7 \pm 3.0$ & $\mathrm{y}=1,964.5 \mathrm{x}-2,956.7$ & 0.9957 \\
$\beta$-Carotene & $99.0 \pm 5.2$ & $\mathrm{y}=2,108.2 \mathrm{x}-3,163.0$ & 0.9979 \\
Retinol & $104.3 \pm 4.1$ & $\mathrm{y}=1,392.8 \mathrm{x}-3,768.9$ & 0.9958 \\
$\alpha$-Tocopherol & $96.5 \pm 4.7$ & $\mathrm{y}=2,407.3 \mathrm{x}-2,511.7$ & 0.9953 \\
\hline
\end{tabular}

$(P<0.05)$. Milks extracted with solutions containing hexane or THF/hexane consistently measured zeaxanthin concentrations below the LoQ. Concentrations of $\beta$-carotene, retinol, and $\alpha$-tocopherol concentrations were consistent between extraction solutions $(P>$ 0.05). Diethyl ether was the most efficient solvent for xanthophyll extraction due to increased zeaxanthin extraction; however, dichloromethane may be as effective as diethyl ether in lutein extraction when zeaxanthin is not needed.

Mean percent recovery of lutein, zeaxanthin, $\beta$-carotene, retinol, and $\alpha$-tocopherol from whole milk was $98.4,91.7,99,104.3$, and $96.5 \%$, respectively (Table 3). Mean RSD for reproducibility of peak area between days for lutein was 3.25 and $3.79 \%$ for zeaxanthin (Table 4). Mean RSD of repeatability on the same day of peak area for lutein and zeaxanthin were 1.45 and $1.86 \%$, respectively. The RSD for reproducibility of peak area analyzed on the same day was below 3.0\% for all compounds tested. These RSD values are similar to those reported by Gill and Indyk (2008), ChauveauDuriot et al. (2010), and Indyk (1987). Although these RSD values were similar, the previous studies did not define parameters that would allow for the extraction and detection of both $\beta$-carotene and xanthophylls simultaneously. Our proposed optimized method allows for accurate extraction and detection of $\beta$-carotene and lutein and zeaxanthin with a single extraction technique.

The LoD and LoQ of lutein under the imposed conditions were 0.33 and $0.77 \mu \mathrm{g} / 100 \mathrm{~mL}$, respectively
(Table 5). The values are similar to the LoQ for lutein reported by Gill and Indyk (2008) of $1.4 \mu \mathrm{g} / 100 \mathrm{~g}$, but lower than other reported LoQ values for lutein (Chauveau-Duriot et al., 2010). Gill and Indyk (2008) reported a technique that used a variance of previously defined parameters to investigate the amount of lutein and zeaxanthin in bovine milks, whereas ChauveauDuriot et al. (2010) were able to vary parameters to find carotenoids and lutein to a lesser extent but not zeaxanthin. The LoD and LoQ of zeaxanthin for the current method were 0.26 and $0.74 \mu \mathrm{g} / 100 \mathrm{~mL}$, respectively, which is also lower than previously published LoQ values (Indyk, 1987; Chauveau-Duriot et al., 2010). The LoQ for $\beta$-carotene, retinol, and $\alpha$-tocopherol were within ranges observed in other published methods (Indyk, 1987; Chauveau-Duriot et al., 2010). We addressed the limitations previously defined in literature; specifically, the optimization parameters for lutein and zeaxanthin extraction simultaneously with $\beta$-carotene in milks of TMR-fed cows are documented, allowing for sensitive detection and determination of xanthophylls in a matrix where it is currently not reliable.

The concentrations of lutein, zeaxanthin, $\beta$-carotene, retinol, and $\alpha$-tocopherol were determined in $10 \mathrm{com}$ mercial pasteurized milks using the developed method (Table 6; Figures 1, 2). Using this method, lutein was consistently found above the LoQ, with concentrations ranging from 1.97 to $2.71 \mu \mathrm{g} / 100 \mathrm{~mL}$ in milks of pasture-fed cows to 1.52 to $1.83 \mu \mathrm{g} / 100 \mathrm{~mL}$ in milks of TMR-fed cows. These results were similar to previous studies (Nozière et al., 2006; Gill and Indyk, 2008),

Table 4. Retention time, wavelength for measurement, and reproducibility of method in whole pasteurized bovine milk $(\mathrm{n}=6)$

\begin{tabular}{lcccc}
\hline & & \multicolumn{2}{c}{$\begin{array}{c}\text { Peak area reproducibility } \\
\text { (relative SD\%) }\end{array}$} \\
\cline { 4 - 5 } Compound & $\begin{array}{c}\text { Mean retention } \\
\text { time (min) }\end{array}$ & $\begin{array}{c}\text { Wavelength for } \\
\text { measurement (nm) }\end{array}$ & Between days & Same day \\
\hline Lutein & 1.35 & 444 & 3.25 & 1.45 \\
Zeaxanthin & 1.43 & 448 & 3.79 & 1.86 \\
B-Carotene & 3.23 & 448 & 2.02 & 2.02 \\
Retinol & 1.56 & 325 & 3.13 & 2.08 \\
$\alpha$-Tocopherol & 1.82 & 294 & 4.17 & 1.31 \\
\hline
\end{tabular}


Table 5. Limit of detection (LoD) and quantification (LoQ) of the proposed method in whole pasteurized bovine milk $(\mathrm{n}=6)$

\begin{tabular}{lcc}
\hline Compound & $\begin{array}{c}\text { LoD } \\
(\mu \mathrm{g} / 100 \mathrm{~mL})\end{array}$ & $\begin{array}{c}\text { LoQ } \\
(\mu \mathrm{g} / 100 \mathrm{~mL})\end{array}$ \\
\hline Lutein & 0.33 & 0.77 \\
Zeaxanthin & 0.26 & 0.74 \\
$\beta$-Carotene & 0.30 & 0.63 \\
Retinol & 0.33 & 0.83 \\
$\alpha$-Tocopherol & 0.57 & 1.19 \\
\hline
\end{tabular}

where both authors investigated carotenoids but not zeaxanthin. Zeaxanthin was detected in $66 \%$ of the milks tested, but only $56 \%$ were measured above the LoQ, ranging from 0.75 to $1.08 \mu \mathrm{g} / 100 \mathrm{~mL}$. Three commercial milks from TMR-fed cows had zeaxanthin above the LoD by our proposed optimized method and only 1 contained zeaxanthin above the LoQ. Several studies have reported zeaxanthin consistently not detected or being below the LoQ (Gill and Indyk, 2008; ChauveauDuriot et al., 2010; Nozière et al., 2006). Our optimized method consistently allowed for simultaneous detection of $\beta$-carotene with the xanthophylls, lutein and zeaxanthin. An increase in the LOD for zeaxanthin achieved from our proposed method is possibly due to increasing the initial sample volume, causing the increase in zeaxanthin into an observable range not noted in previous research.

Consistent with other published research, approximately $70 \%$ of the measured carotenoid weight was from $\beta$-carotene (Calderón et al., 2006). Mean concentration of $\beta$-carotene in milk of pasture-fed cows was $63 \%$ higher than in milk of TMR-fed cows $(P<0.05)$, similar to observations by Bergamo et al. (2003). Concentrations of $\alpha$-tocopherol ranged from 24.9 to 63.5 $\mu \mathrm{g} / 100 \mathrm{~mL}$ in samples tested and were $39 \%$ higher in milk of pasture-fed cows than in milk of TMR-fed cows, consistent with previous research (Bergamo et al., 2003). Although $\alpha$-tocopherol was the only form of vitamin E reported in our study, $\gamma$-tocopherol was identified in several milks from pasture-fed cows, consistent with Chauveau-Duriot et al. (2010). Concentrations of retinol between milks of pasture- and TMR-fed cows were not different $(P>0.05)$, comparable to previous research (Delgado Zammarreño et al., 1992; Bergamo et al., 2003).

An efficient method was developed to consistently detect lutein simultaneously with other carotenoids and vitamins in milk. Zeaxanthin was detected in $66 \%$ of milk tested, with $56 \%$ of the samples above the LoQ. Optimal saponification parameters from milk for xanthophyll detection were 40 to $50^{\circ} \mathrm{C}$ with a caustic solution containing $25 \% \mathrm{KOH}$. These parameters were also optimal for $\beta$-carotene, retinol, and $\alpha$-tocopherol extraction from the fat matrix of milk. Extraction solutions (following saponification) containing diethyl ether had the highest concentration of zeaxanthin $(P<0.05)$, and extraction solutions containing diethyl ether or dichloromethane had the highest concentration of lutein $(P<0.05)$. Concentrations of $\beta$-carotene, retinol, and $\alpha$-tocopherol were unaffected by extraction solution ( $P$ $>0.05$ ). This method was developed and verified to consistently measure lutein above the LoQ in milks of TMR-fed cows without affecting recovery of $\beta$-carotene, retinol, and $\alpha$-tocopherol.

\section{ACKNOWLEDGMENTS}

Funding was provided in part by the National Dairy Council (NDC; formerly Dairy Management Inc., Rosemont, IL).

Table 6. Mean concentrations of vitamins and carotenoids of 10 whole commercial bovine milks $(\mathrm{n}=30)$

\begin{tabular}{|c|c|c|c|c|c|c|}
\hline $\begin{array}{l}\text { Sample } \\
\text { number }\end{array}$ & $\begin{array}{l}\text { TMR or } \\
\text { pasture }\end{array}$ & $\begin{array}{c}\text { Lutein } \\
(\mu \mathrm{g} / 100 \mathrm{~mL})\end{array}$ & $\begin{array}{l}\text { Zeaxanthin } \\
(\mu \mathrm{g} / 100 \mathrm{~mL})\end{array}$ & $\begin{array}{l}\beta \text {-Carotene } \\
(\mu \mathrm{g} / 100 \mathrm{~mL})\end{array}$ & $\begin{array}{c}\text { Retinol } \\
(\mu \mathrm{g} / 100 \mathrm{~mL})\end{array}$ & $\begin{array}{r}\alpha \text {-Tocopherol } \\
(\mu \mathrm{g} / 100 \mathrm{~mL})\end{array}$ \\
\hline 1 & TMR & $1.59^{\mathrm{CD}}$ & $\mathrm{ND}^{1}$ & $8.06^{\mathrm{C}}$ & $17.30^{\mathrm{D}}$ & $35.48^{\mathrm{D}}$ \\
\hline 2 & TMR & $1.73^{\mathrm{CD}}$ & $\mathrm{NQ}^{2}$ & $8.84^{\mathrm{C}}$ & $18.11^{\mathrm{CD}}$ & $32.80^{\mathrm{DE}}$ \\
\hline 4 & TMR & $1.57^{\mathrm{D}}$ & ND & $9.04^{\mathrm{C}}$ & $18.81^{\mathrm{CD}}$ & $39.90^{\mathrm{D}}$ \\
\hline 5 & TMR & $1.77^{\mathrm{CD}}$ & ND & $5.89^{\mathrm{D}}$ & $33.14^{\mathrm{A}}$ & $26.30^{\mathrm{E}}$ \\
\hline 6 & Pasture & $2.29^{\mathrm{B}}$ & $0.87^{\mathrm{BC}}$ & $11.52^{\mathrm{B}}$ & $20.39^{\mathrm{CD}}$ & $49.56^{\mathrm{BC}}$ \\
\hline \multirow[t]{3}{*}{10} & Pasture & $2.55^{\mathrm{A}}$ & $0.92^{\mathrm{B}}$ & $14.62^{\mathrm{A}}$ & $21.50^{\mathrm{C}}$ & $40.98^{\mathrm{CD}}$ \\
\hline & $P>\mathrm{F}$ & $<0.0001$ & $<0.0001$ & $<0.0001$ & $<0.0001$ & $<0.0001$ \\
\hline & $\mathrm{R}^{2}$ & 0.927 & 0.988 & 0.915 & 0.872 & 0.873 \\
\hline
\end{tabular}

\footnotetext{
${ }^{\mathrm{A}-\mathrm{E}}$ Means in a column not sharing a common letter are different $(P<0.05)$.

${ }^{1} \mathrm{ND}=$ not detected.

${ }^{2} \mathrm{NQ}=$ not quantified. Samples were detected, but were measured below LoQ.
} 


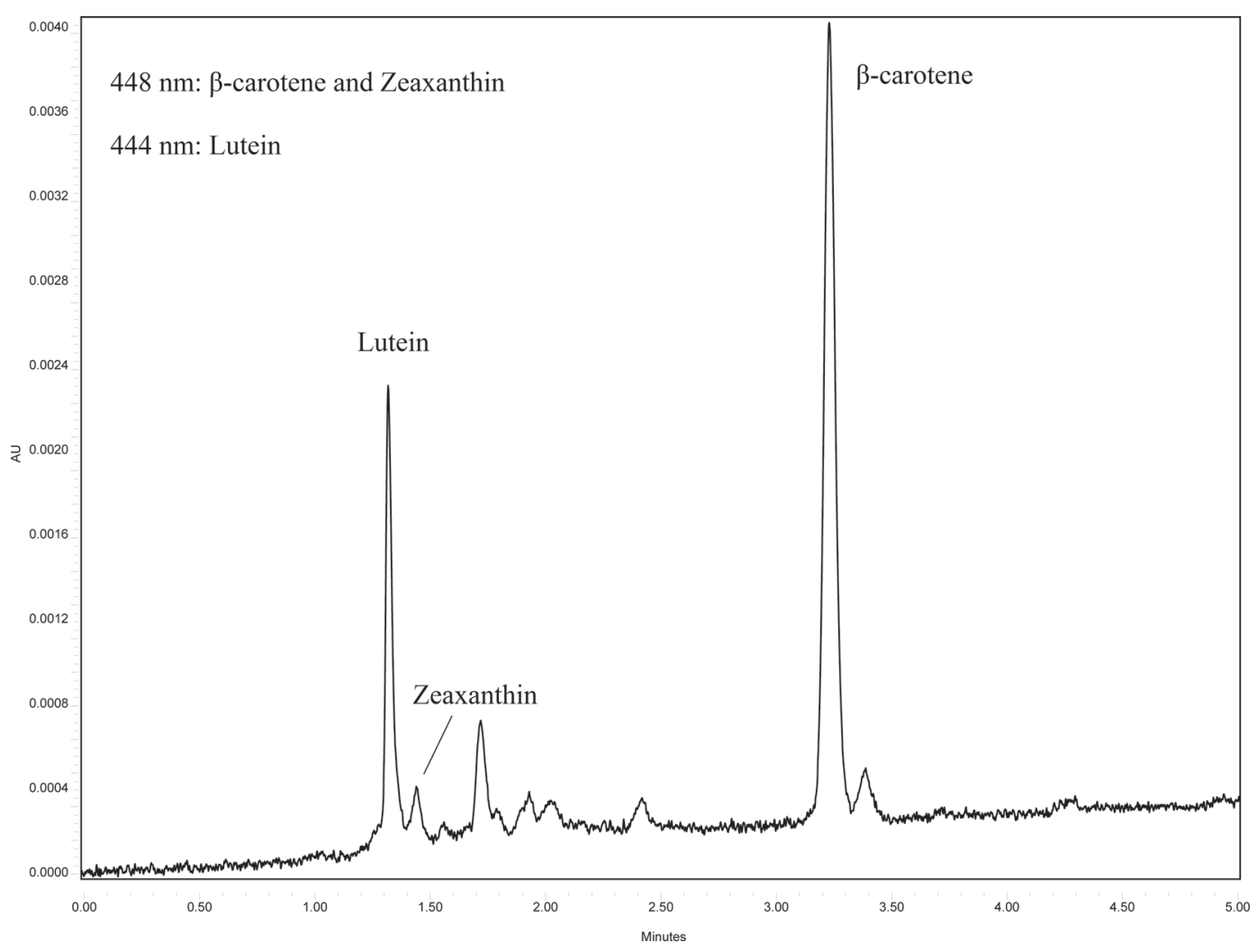

Figure 1. Chromatogram of lutein, zeaxanthin, and $\beta$-carotene from milk of cows fed a TMR.

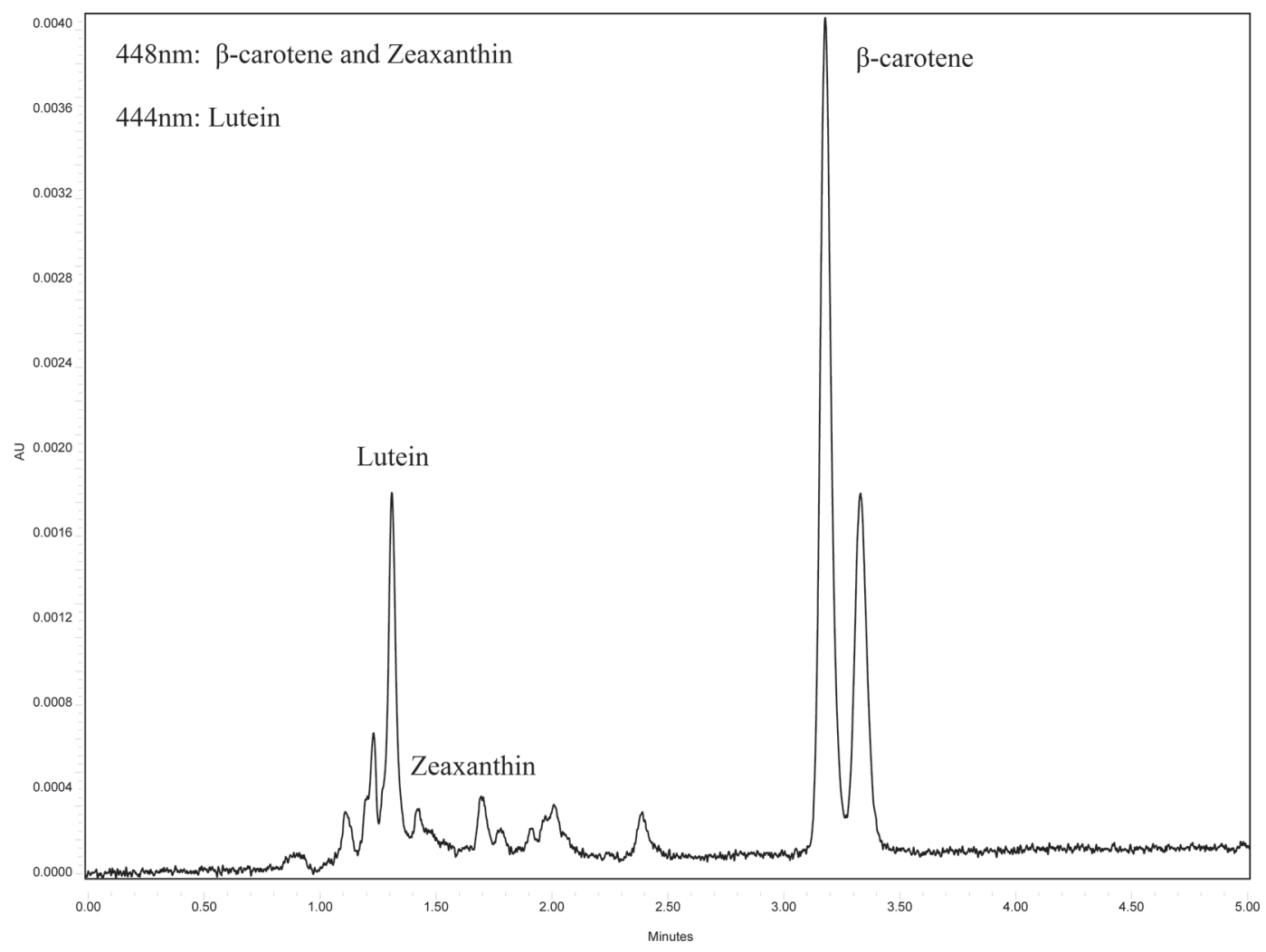

Figure 2. Chromatogram of lutein, zeaxanthin, and $\beta$-carotene of milk from cows fed pasture. 


\section{REFERENCES}

Bergamo, P., E. Fedele, L. Iannibelli, and G. Marzillo. 2003. Fat-soluble vitamin content and fatty acid composition in organic and conventional Italian dairy products. Food Chem. 82:625-631.

Blake, C. J. 2007. Status of methodology for the determination of fatsoluble vitamins in foods, dietary supplements and vitamin premixes. J. AOAC Int. 90:897-910.

Butler, G., J. Nielsen, T. Slots, C. Seal, M. Eyre, R. Sanderson, and L. Leifert. 2008. Fatty acid and fat-soluble antioxidant concentrations in milk from high- and low-input conventional and organic systems: seasonal variation. J. Sci. Food Agric. 88:1431-1441. https://doi.org/10.1002/jsfa.3235.

Calderón, F., B. Chauveau-Duriot, B. Martin, B. Graulet, M. Doreau, and P. Nozière. 2007b. Variations in carotenoids, vitamins A and $\mathrm{E}$, and color in cow's plasma and milk during late pregnancy and the first three months of lactation. J. Dairy Sci. 90:2335-2346.

Calderón, F., B. Chauveau-Duriot, P. Pradel, B. Martin, B. Graulet, M. Doreau, and P. Nozière. 2007a. Variations in carotenoids, vitamins A and E, and color in cow's plasma and milk following a shift from ay diet to diets containing increasing levels of carotenoids and vitamin E. J. Dairy Sci. 90:5651-5664.

Calderón, F., G. Tornambé, B. Marin, P. Pradel, B. Chauveau-Duriot, and P. Noziére. 2006. Effects of mountain grassland maturity stage and grazing management on carotenoids in sward and cow's milk. Anim. Res. 55:533-544.

Chauveau-Duriot, B., M. Doreau, P. Nozière, and B. Graulet. 2010. Simultaneous quantification of carotenoids, retinol, and tocopherols in forages, bovine plasma, and milk: validation of a novel UPLC method. Anal. Bioanal. Chem. 397:777-790.

Craft, N., and J. H. Soares. 1992. Relative solubility, stability, and absorptivity of lutein and $\beta$-carotene in organic solvents. J. Agric. Food Chem. 40:431-434.

Gentili, A., F. Caretti, S. Bellante, S. Ventura, S. Canepari, and R. Curini. 2013. Comprehensive profiling of carotenoid and fat-soluble vitamins in milk from different animal species by LC-DADMS/MS Hyphenation. J. Agric. Food Chem. 61:1628-1639.

Gill, B. D., and H. E. Indyk. 2008. Liquid chromatographic method for the determination of lutein in milk and pediatric formulas. Int. Dairy J. 18:894-898.

Gill, B. D., H. E. Indyk, and D. C. Woollard. 2016. Current methods for the analysis of selected novel nutrients in infant formulas and adult nutritionals. J. AOAC Int. 99:30-41.

Giuliano, A. R., E. M. Neilson, B. E. Kelly, and L. M. Canfield. 1992. Simultaneous quantitation and separation of carotenoids and retinol in human milk by high-performance liquid chromatography. Methods Enzymol. 213:391-399.

Granelli, K., and S. Helmersson. 1996. Short communication: Rapid high-performance liquid chromatographic method for determination of $\beta$-carotene in milk. J. Chromatogr. A 721:355-358.

Havemose, M. S., M. R. Weisbjerg, W. L. P. Bredie, and J. H. Nielsen. 2004. Influence of feeding different types of roughage on the oxidative stability of milk. Int. Dairy J. 14:563-570.

Indyk, H. E. 1987. The rapid determination of carotenoids in bovine milk using HPLC. J. Micronutr. Anal. 3:169-183.

Jewell, V. C., C. B. Mayes, T. R. Tubman, C. A. Northrop-Clewes, and D. I. Thurnham., 2004. A comparison of lutein and zeaxanthin concentrations in formulas and human milk samples from Northern Ireland mothers. Eur. J. Clin. Microbiol. Infect. Dis. 58:90-97

Jinno, K., and Y. Lin. 1995. Separation of carotenoids by high-performance liquid chromatography with polymeric and monomeric octadecylsilica stationary phases. Chromatographia 41:311-317.

Kamao, M., N. Tsugawa, Y. Suhara, A. Wada, T. Mori, K. Murata, R. Nishino, T. Ukita, K. T. Uenishi, and T. Okano. 2007. Quantification of fat-soluble vitamins in human breast milk by liquid chromatography-tandem mass spectrometry. J. Chromatogr. B 859:192-200. https://doi.org/10.1016/j.jchromb.2007.09.023
Khachik, F., C. J. Spangler, and J. C. Smith. 1997. Identification, quantification, and relative concentrations of carotenoids and their metabolites in human milk and serum. Anal. Chem. 69:1873-1881.

Kohlmeier, L., and S. B. Hastings. 1995. Epidemiologic evidence of a role of carotenoids in cardiovascular disease prevention. Am. J. Clin. Nutr. 62:1370S-1376S.

MacCrehan, W. A., and E. Schönberger. 1987. Determination of retinol, alpha-tocopherol, and beta-carotene in serum by liquid chromatography with absorbance and electrochemical detection. Clin. Chem. 33:1585-1592.

Macias, C., and F. J. Schweigert. 2001. Changes in the concentration of carotenoids, vitamin A, alpha-tocopherol and total lipids in human milk throughout early lactation. Ann. Nutr. Metab. 45:82-85. https://doi.org/10.1159/000046711.

Martin B., A. Cornu, N. Kondjoyan, A. Ferlay, I. Verdier-Metz, P. Pradel, E. Rock, Y. Chilliard, B. Coulon, and J. L. Berdagué. 2005. Milk indicators for recognizing the types of forages eaten by dairy cows. Pages 127-136 in Indicators of Milk and Beef Quality. J. F. Hocquette and S. Gigli, ed. EAAP Publ. 112. EAAP, Wageningen, the Netherlands.

Mortensen, A., and L. H. Skibsted. 1997. Free radical transients in photobleaching of xanthophylls and carotenes. Free Radic. Res. $26: 549-563$.

Nozière, P., P. Grolier, D. Durand, A. Ferlay, P. Pradel, and B. Martin. 2006. Variations in carotenoids, fat-soluble micronutrients, and color in cows' plasma and milk following changes in forage and feeding level. J. Dairy Sci. 89:2634-2648.

Oliver, J., and A. Palou. 2000. Chromatographic determination of carotenoids in foods. J. Chromatogr. A 881:543-555.

Ollilainen, V., M. Heinonen, E. Linkola, P. Varo, and P. Koivistoinen. 1989. Retinoids and carotenoids in Finnish foods: fish and fish products. J. Food Compos. Anal. 2:93-103.

Plozza, T., V. C. Trenerry, and D. Caridi. 2012. The simultaneous determination of vitamins $\mathrm{A}, \mathrm{E}$ and $\beta$-carotene in bovine milk by high performance liquid chromatography-ion trap mass spectrometry (HPLC-MS ${ }^{\mathrm{n}}$ ). Food Chem. 134:559-563.

Prache, S., A. Priolo, H. Tournadre, R. Jailler, H. Dubroeucq, D. Micol, and B. Martin. 2002. Traceability of grass feeding by quantifying the signature of carotenoid pigments in herbivore meat, milk and cheese. Pages 592-593 in Proceedings of the 19th General Meeting of the European Grassland Federation, La Rochelle. J. L. Durand, J. C. Emile, C. Huyghe, and Lemaire, ed. Arbeitsgemeinshaft zur Foderung des Futterbaues, Zurich, Switzerland.

Rapp, L. M., S. Seema, and J. H. Choi. 2000. Lutein and zeaxanthin concentration in rod outer segment membranes from perifoveal and peripheral human retina. Invest. Ophthalmol. Vis. Sci. 41:1200-1209.

Salo-Väänänena, P., V Ollilainena, P Mattilab, K Lehikoinenc, E Salmela-Mölsäa, and V. Piironena. 2000. Simultaneous HPLC analysis of fat-soluble vitamins in selected animal products after small-scale extraction. Food Chem. 71:535-543.

Schweigert, F. J., K. Bathe, F. Chen, U. Büscher, and J. W. Dudenhausen. 2004. Effect of the stage of lactation in humans on carotenoid levels in milk, blood plasma and plasma lipoprotein fractions. Eur. J. Nutr. 43:39-44. https://doi.org/10.1007/s00394-004 $-0439-5$.

Turne, C., J. W. King, and L. Mathiasson. 2001. Supercritical fluid extraction and chromatography for fat-soluble vitamin analysis. J. Chromatogr. A 936:215-237. https://doi.org/10.1016/S0021 -9673(01)01082-2.

Yan, H., P. Zhang, C. Wang, Z. Liu, and W. Chang. 2007. Two lutein molecules in LHCII have different conformations and functions: insights into the molecular mechanism of thermal dissipation in plants. Biochem. Biophys. Res. Commun. 355:457-463.

Delgado Zammarreño, M. M., A. S. Pérez, C. G. Pérez, and J. Hernández. 1992. High-performance liquid chromatography with electrochemical detection for the simultaneous determination of vitamin $\mathrm{A}, \mathrm{D}_{3}$, and $\mathrm{E}$ in milk. J. Chromatogr. 623:69-74. 